\title{
Quantitative Differences in Immune Responses in Mouse Strains that Differ in their Susceptibility to Trypanosoma brucei brucei Infection
}

\author{
Boniface NAMANGALA ${ }^{1) *}$, Patrick DE BAETSELIER ${ }^{2)}$ and Alain BESCHIN ${ }^{2)}$ \\ ${ }^{1)}$ The University of Zambia, Faculty of Veterinary Medicine, Department of Paraclinical Studies, Box 32379, Lusaka, Zambia and \\ ${ }^{2)}$ Department of Cellular and Molecular Interactions, Flanders Interuniversity Institute for Biotechnology (VUB), Laboratory of Cellular \\ Immunology, Pleinlaan 2, B-1050, Brussels, Belgium
}

(Received 27 April 2008/Accepted 18 March 2009)

\begin{abstract}
We compared the relative resistance and soluble variant surface glycoprotein (VSG)-specific responses in (C57BL/6 $\times$ BALB/ c)-F1 (B6B-F1) and C3H mice during infection with Trypanosoma brucei brucei, the hemoprotozoan parasite causing a debilitating disease in man and livestock. We demonstrated that $\mathrm{C} 3 \mathrm{H}$ mice are relatively more trypanosusceptible, as evidenced by their reduced ability to control parasitemia and shorter survival time, than B6B-F1 mice. Quantitative differences in the pattern of cytokine and antibody (Ab) production were observed between the 2 mouse strains following infection with $T$. b. brucei. Thus, although both mouse strains recorded detectable levels of IFN- $\gamma$, TNF- $\alpha$, NO and IL-10 in plasma and lymph nodes, as well as plasma IgM, IgG1, IgG2a, IgG2b and IgG3 Abs against VSG, the susceptible $\mathrm{C} 3 \mathrm{H}$ mice only exhibited trace levels of Abs of all isotypes and yet produced elevated levels of IFN$\gamma, \mathrm{TNF}-\alpha$ and NO, compared to the relatively trypanotolerant B6B-F1 mice. In aggregate, these data strongly suggest that trypanosomeinfected $\mathrm{C} 3 \mathrm{H}$ mice have an immunological defect, manifested not only by suppression at the $\mathrm{B}$ cell clonal level, but also at the level of protective $\mathrm{T}$ cell and macrophage phenotypes.

KEY WORDS: Anti-VSG antibody, cytokines, quantitative, Trypanosoma brucei brucei, trypanotolerant.
\end{abstract}

J. Vet. Med. Sci. 71(7): 951-956, 2009

Recent studies suggest that during infection with African trypanosomes such as Trypanosoma brucei species that afflict both man and animals, resistant and susceptible animals differentially produce cytokines including interferon gamma (IFN- $\gamma$ ), tumor necrosis factor (TNF)- $\alpha$, interleukin (IL)-4, IL-10 and IL-12 [2, 3, 19]. Th1 cytokines such as IFN- $\gamma$ have been linked with resistance to $T . b$. rhodesiense in mice [3]. However, Uzonna et al. [19, 20] correlated this cytokine with susceptibility to $T$. congolense infection while TNF- $\alpha$ and IL-12 were associated with resistance. Yet other studies have linked IFN- $\gamma$ and TNF- $\alpha$ via macrophage hyperactivation and nitric oxide (NO) production $[15,16]$, as well as IL-10 via immunodepression [21], with the pathogenesis of African trypanosomosis. Type- 2 cytokines such as IL-4 and IL-10 have also been linked with resistance during African trypanosomosis $[9,16]$. However, Hertz et al. [3] showed that IL-4 was not involved in protection or susceptibility to $T$. $b$. rhodesiense infection.

Because inbred mouse strains differ markedly in their relative susceptibility to infection with African trypanosomes [19] and since similar differences in trypanosusceptibility occur among the various cattle breeds in sub-Saharan Africa [18], it is of practical importance to identify the mechanisms underlying this phenomenon. We previously reported that F1 cross between C57BL/6 and BALB/c (B6B-F1) mice tend to exhibit a more resistant phenotype to trypanosome infections than their parental $\mathrm{C} 57 \mathrm{BL} / 6$ and $\mathrm{BALB} / \mathrm{c}$ mouse strains [9]. In contrast to $\mathrm{B} 6 \mathrm{~B}-\mathrm{F} 1, \mathrm{C} 3 \mathrm{H}$ mice are among the

\footnotetext{
* Correspondence to: Namangala, B., The University of Zambia, Faculty of Veterinary Medicine, Department of Paraclinical Studies, Box 32379, Lusaka, Zambia.

e-mail: boniface_1020@yahoo.com
}

most trypanosusceptible mouse strains [8]. To gain insights into the mechanisms underlying tolerance to African trypanosomosis, we evaluated the VSG-specific cytokine and $\mathrm{Ab}$ secretion in the relatively resistant $\mathrm{B} 6 \mathrm{~B}-\mathrm{F} 1$ mice and the susceptible $\mathrm{C} 3 \mathrm{H}$ mice upon infection with $T$. b. brucei. We show that quantitative differences in both $\mathrm{Ab}$ and cytokine production do exists between the two mouse strains during T. b. brucei infection. The possible mechanisms of resistance and susceptibility are discussed.

\section{MATERIALS AND METHODS}

Animals and parasites: Eight-weeks old female (C57BL/ $6 \times \mathrm{BALB} / \mathrm{c})-\mathrm{F} 1$ (B6B-F1) or $\mathrm{C} 3 \mathrm{H} / \mathrm{HeN}(\mathrm{C} 3 \mathrm{H})$ (Harlon, The Netherlands) were inoculated intraperitoneally (ip) with $2 \times 10^{3}$ AnTat 1 T. b. brucei. Parasitemia was monitored by tail blood puncture every 2-4 days using a hemocytometer. All animal experiments were conducted in accordance with the Standards relating to the Care and Management of Experimental Animals of Free University of Brussels (VUB, Brussels, Belgium).

Experimental design: At different times post-infection (pi), cytokine, antibody and NO levels were analyzed in 5 infected mice. For each parameter, results were expressed as the mean response of the 5 infected animals tested individually $( \pm$ SE) and compared to the same parameters assessed in 5 uninfected mice. Results are representative of at least 5 similar experiments performed. Statistical analyses were assessed using a PRISM computer program (GraphPad) to validate the data. $P$-values of $<0.05$ were considered statistically significant.

Plasma collection and cell preparation: During early (2 
weeks pi) and late (4 weeks pi) stages of infection, blood collected by heart puncture on 20 units $/ \mathrm{m} l$ heparin (Sigma, St. Louis, MS) was centrifuged $(10,000 \times \mathrm{g}, 10 \mathrm{~min})$ and the plasma stored at $-80^{\circ} \mathrm{C}$ until analysis. Mesenteric and peripheral (axial and inguinal) lymph node single-cell suspensions (LNC) were prepared as described [1].

Cell cultures for soluble cytokine quantification: During early and late stages of infection, $4 \times 10^{5} \mathrm{LNC}$ from infected $\mathrm{C} 3 \mathrm{H}(\mathrm{C} 3 \mathrm{H}-\mathrm{LNCi})$ or B6B-F1 (B6B-F1-LNCi) mice were cultured with or without $50 \mu \mathrm{g} / \mathrm{m} l$ soluble AnTat $1 \mathrm{VSG}$ prepared as described [8]. The single lot preparation of VSG was used throughout the study. Lipopolysaccharide contamination of VSG was below the detection limit of the Kinetic-QCL LAL test (Bio-Whittaker Europe, Verviers, Belgium). LNC from uninfected mice ( $\mathrm{LNCn}$ ) were used as controls. Cultures were incubated at $37^{\circ} \mathrm{C}$ in a humidified atmosphere containing $5 \% \mathrm{CO}_{2}$ and culture supernatants collected after $72 \mathrm{hr}$ and frozen at $-20^{\circ} \mathrm{C}$ until analysis.

Quantification of cytokines: Cytokines were quantified in the plasma or cell culture supernatants using cytokine-specific sandwich ELISA. The reagents were purchased from PharMingen Europe, Erembodegem-Aalst, Belgium (IFN- $\gamma$, IL-10) or R\&D Systems, Abingdon, UK (TNF- $\alpha$ ) and ELISA assays performed following the manufacture's suggested protocols.

Determination of antibody isotypes: Plasma from infected (day 10 pi) and uninfected mice were tested in antibody isotype-specific ELISAs for VSG reactivity. Briefly, ELISA plates were coated with AnTat $1 \mathrm{VSG}(5 \mu \mathrm{g} / \mathrm{m} l)$ at $4{ }^{\circ} \mathrm{C}$ overnight. Plates were washed $(0.01 \%$ tween 20 in PBS), blocked with $10 \%$ bovine fetal calf serum in PBS (1 $\mathrm{hr}, 37^{\circ} \mathrm{C}$ ) and washed again. Plasma samples (diluted $100 \times$ in PBS containing $2 \%$ bovine fetal calf serum) were added to the plates $\left(1 \mathrm{hr}, 37^{\circ} \mathrm{C}\right)$ followed by another wash. Horseradish peroxidase conjugated rat-anti-mouse isotype-specific antibodies (Southern Biotechnology, Birmingham,
AL) were added $\left(1 \mathrm{hr}, 37^{\circ} \mathrm{C}\right)$. After washing, the assay was developed by adding 3,3',5,5'-tetramethylbenzidine (Sigma). For each sample, the optical density (OD, $490 \mathrm{~nm}$ ) determined on bovine albumin-coated plates was subtracted from the OD values obtained on VSG-coated plates.

Plasma NO measurement: To determine plasma NO levels, nitrate was stoichemetrically reduced to nitrite by incubating $100 \mu \mathrm{l}$ of plasma sample for $1 \mathrm{hr}$ at $37^{\circ} \mathrm{C}$ in presence of $0.1 \mathrm{U} / \mathrm{m} l$ of Aspergillus nitrite reductase (NAD[P]H, EC 1.6.6.2; Sigma); $120 \mu \mathrm{M}$ reduced nicotinamide adenine dinucleotide phosphate (NADPH) and $5 \mu \mathrm{M}$ flavine adenine dinucleotide (FAD). Subsequently, excess NADPH was oxidized with $10 \mathrm{U} / \mathrm{m} l$ L-lactic dehydrogenase (EC 1.1.1.27; type XI, from rabbit muscle; Sigma) and $10 \mathrm{mM}$ sodium pyruvate (Sigma) for 30 minutes at $37^{\circ} \mathrm{C}$. Nitrite concentration in plasma was assayed by a standard Griess reaction [6].

\section{RESULTS}

C3H mice are more susceptible to T. b. brucei infection than B6B-F1 mice: The course of T. b. brucei infection was evaluated in $\mathrm{B} 6 \mathrm{~B}-\mathrm{F} 1$ and $\mathrm{C} 3 \mathrm{H}$ mice. Although both mouse strains had similar prepatent periods, $\mathrm{C} 3 \mathrm{H}$ mice appeared more susceptible to $T$. $b$. brucei infection as evidenced by their significantly higher first parasitemic peak than their B6B-F1 counterparts $(\mathrm{p}<0.01$, Table 1, Fig. 1). Furthermore, despite managing to significantly reduce the first peak of parasitemia, T. b. brucei-infected $\mathrm{C} 3 \mathrm{H}$ mice failed to control the second peak of parasitemia and died after about 25 days pi, with massive parasitosis. In contrast, $T$. b. bruceiinfected B6B-F1 mice exhibited comparatively shorter time to first remission $(\mathrm{p}<0.001)$, stronger ability to control parasite proliferation and increased survival rate $(\mathrm{p}<0.05)$.

T. b. brucei-infected $\mathrm{C} 3 \mathrm{H}$ mice produce higher levels of $V S G$-specific IFN- $\gamma$ and TNF- $\alpha$ in lymph node cell cultures

Table 1. Parasitemia dynamics and survival time of T. b. brucei AnTat 1 infected B6B-F1 versus $\mathrm{C} 3 \mathrm{H}$ mice

\begin{tabular}{lcc}
\hline Parameter & \multicolumn{2}{c}{ Mouse $\operatorname{strain}^{\#}$} \\
\hline & BC6-F1 ${ }^{\text {a) }}$ & C3H ${ }^{\text {a) }}$ \\
\hline Prepatent period (days) & $3.3 \pm 0.3$ & $2.7 \pm 0.3$ \\
Time to first peak of parasitemia (days) & $5.0 \pm 0.4$ & $6.3 \pm 0.2^{\text {b) }}$ \\
Level of first peak of parasitemia $\left(\times 10^{6} / \mathrm{m} l\right)$ & $300.0 \pm 22.0$ & $\left.500 \pm 29.4^{\mathrm{c}}\right)$ \\
Time to first remission of parasitemia $($ days $)$ & $10.2 \pm 0.3$ & $13.8 \pm 0.5^{\text {d) }}$ \\
Levels of first remission of parasitemia $\left(\times 10^{6} / \mathrm{m} l\right)$ & $0.0^{*}$ & $15.5 \pm 0.5$ \\
Time to first recrudescence of parasitemia $($ days $)$ & $13.7 \pm 0.5$ & $13.2 \pm 0.3$ \\
Level of first recrudescence of parasitemia $\left(\times 10^{6} / \mathrm{m} l\right)$ & $10.0 \pm 5.0$ & $119.0 \pm 10.0^{\text {e) }}$ \\
Survival time (days) & $35.0 \pm 2.9$ & $25.0 \pm 1.2^{\text {f) }}$ \\
\hline
\end{tabular}

\# Each mouse was intraperitoneally injected with T. b. brucei AnTat 1

a) Mean $\pm \mathrm{SE}(\mathrm{n}=10)$, representative of five independent experiments.

b) Longer $(\mathrm{p}<0.05)$ as compared to BC6-F1 mice infected with T. b. brucei.

c) Higher $(\mathrm{p}<0.01)$ as compared to BC6-F1 mice infected with T. b. brucei.

d) Longer $(\mathrm{p}<0.001)$ as compared to BC6-F1 mice infected with T. b. brucei.

e) Higher $(\mathrm{p}<0.01)$ as compared to BC6-F1 mice infected with T. b. brucei.

f) Shorter $(\mathrm{p}<0.05)$ as compared to BC6-F1 mice infected with T. b. brucei.

* Below detection limits. 


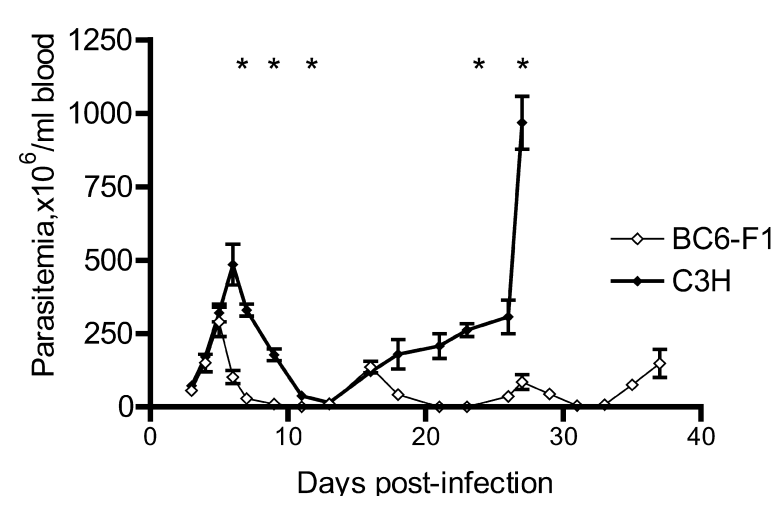

Fig. 1. Parasitemia profiles in $\mathrm{B} 6 \mathrm{~B}-\mathrm{F} 1$ or $\mathrm{C} 3 \mathrm{H}$ mice following infection with Trypanosoma brucei brucei AnTat 1. Statistical analyses were assessed using a PRISM computer program. $P$ values of $<0.05$ were considered statistically significant. Data (mean $\pm \mathrm{SE} ; \mathrm{n}=10$ ) are representative of 5 independent experiments. Asterisks indicate statistically significant difference between the two mouse strains.

than infected $B 6 B-F 1$ mice: We next quantified the cytokine levels in LNC culture supernatants following stimulation with VSG. There was no detectable cytokine in VSG-stimulated LNCn (Fig. 2A-C). Following infection of both mouse strains with $T$. b. brucei, VSG-stimulated LNC mostly secreted IFN- $\gamma$ and TNF- $\alpha$, with only marginal lev- els of IL-10 mainly detected during late stage of infection. However, levels of TNF- $\alpha$ in $\mathrm{C} 3 \mathrm{H}-\mathrm{LNCi}$ culture supernatants were markedly higher than those of B6B-F1-LNCi throughout the entire course of infection. Furthermore, during early stage of infection, $\mathrm{C} 3 \mathrm{H}-\mathrm{LNCi}$ produced significantly higher amounts of IFN- $\gamma$ than B6B-F1-LNCi $(p<0.05)$ although IFN- $\gamma$ levels declined to nearly basal levels in both cases during late stage of infection. Thus, as illustrated in figure 2D, C3H-LNCi cultures exhibited a significantly higher net type-1-skewed cytokine response, characterized by higher IFN- $\gamma / \mathrm{IL}-10$ ratio, than B6B-F1LNCi cultures $(\mathrm{p}<0.05)$.

Plasma levels of IFN- $\gamma$, TNF- $\alpha$ and NO are higher in T. b. brucei-infected $\mathrm{C} 3 \mathrm{H}$ mice than infected B6B-F1 mice: Levels of TNF- $\alpha$, IFN- $\gamma$ and IL-10 in plasma from T. b. brucei-infected B6B-F1 and $\mathrm{C} 3 \mathrm{H}$ mice were evaluated. There were hardly any detectable plasma cytokine levels from uninfected B6B-F1 or $\mathrm{C} 3 \mathrm{H}$ mice (Fig. 3A-C). Although levels of TNF- $\alpha$ were low and comparable in plasma from both mouse strains during early stage of infection, $\mathrm{C} 3 \mathrm{H}$ mice recorded higher plasma TNF- $\alpha$ levels than B6B-F1 mice during late stage of infection $(\mathrm{p}<0.05)$. Furthermore, plasma levels of IFN- $\gamma$ were significantly higher in $\mathrm{C} 3 \mathrm{H}$ than B6B-F1 mice throughout the infection, although the absolute levels declined during late stages of infection. As in LNCi cultures above, IFN- $\gamma / \mathrm{IL}-10$ ratio was higher in the plasma of $\mathrm{C} 3 \mathrm{H}$ mice than that in $\mathrm{B} 6 \mathrm{~B}-\mathrm{F} 1$ mice during the
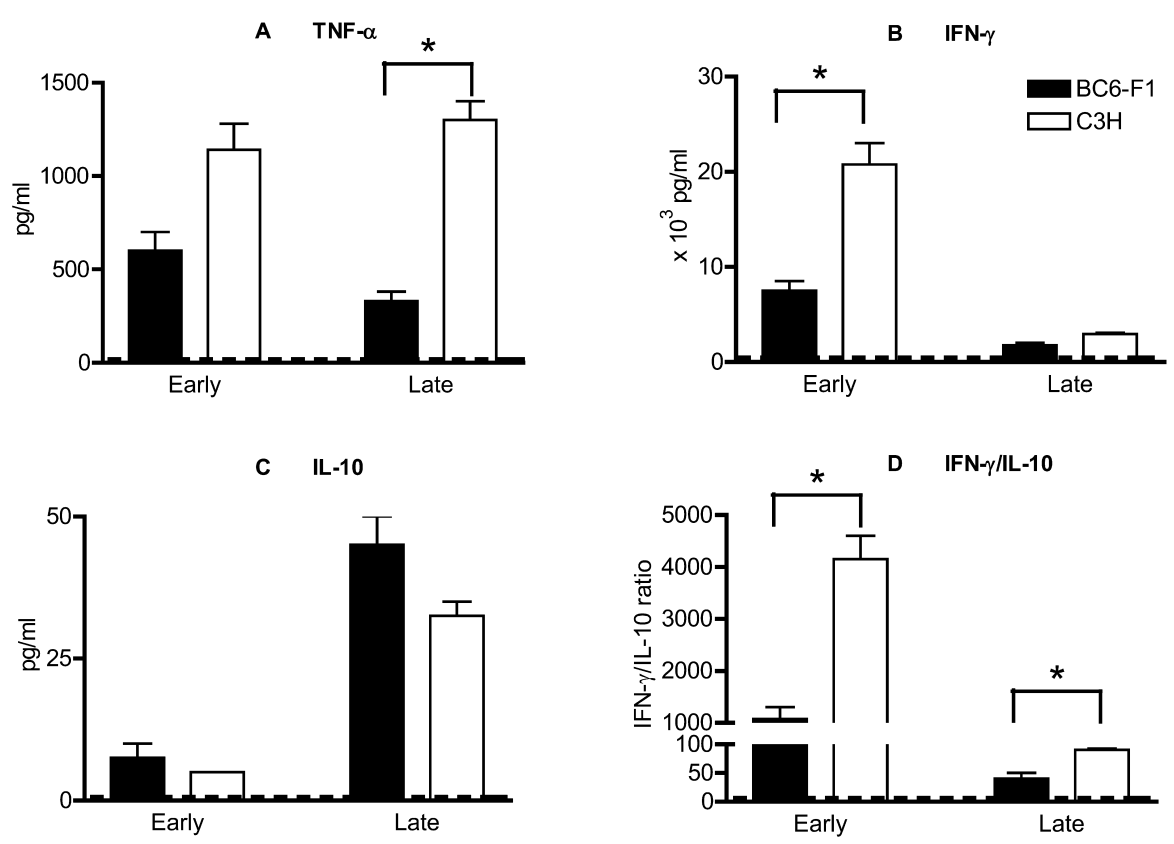

Fig. 2. Effect of Trypanosoma b. brucei infection on cytokine production by VSG-stimulated lymph node cells from B6B-F1 or C3H mice. During early (2 weeks pi) and late (4 weeks pi) stages of infection, lymph node cells from $T$. b. brucei-infected $\mathrm{B} 6 \mathrm{~B}-\mathrm{F} 1$ or $\mathrm{C} 3 \mathrm{H}$ mice were stimulated ex vivo with VSG as described in materials and methods. TNF- $\alpha$ (A), IFN- $\gamma(\mathrm{B})$ and IL-10 (C) production were quantified in culture supernatants and IFN- $\gamma / \mathrm{IL}-10$ (D) ratios calculated. Data (mean $\pm \mathrm{SE} ; n=5)$ are representative of 5 independent experiments. Dashed horizontal lines represent the average cytokine levels in lymph node cell cultures from uninfected mice. Asterisks indicate statistically significant difference between the two mouse strains. 

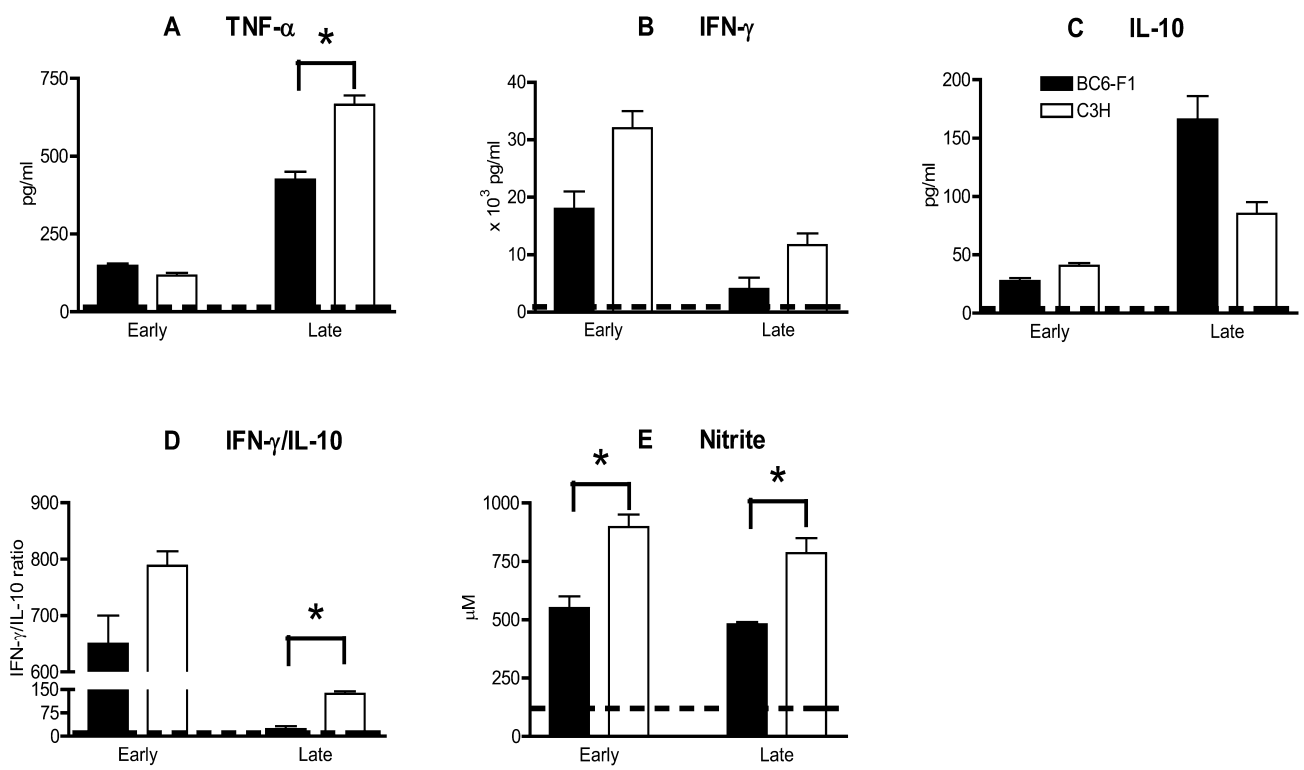

Fig. 3. Plasma levels of cytokines and NO in Trypanosoma b. brucei-infected B6B-F1 or C3H mice. During early (2 weeks pi) and late (4 weeks pi) stages of infection, plasma levels of TNF- $\alpha$ (A), IFN- $\gamma$ (B), IL-10 (C) and $\mathrm{NO}$ (E) were quantified in T. b. brucei-infected B6B-F1 or C3H mice as described in materials and methods and IFN- $\gamma / \mathrm{IL}-10$ (D) ratios calculated. Data (mean $\pm \mathrm{SE} ; \mathrm{n}=5)$ are representative of 5 independent experiments. Dashed horizontal lines represent the average cytokine levels in lymph node cell cultures from uninfected mice. Asterisks indicate statistically significant difference between the two mouse strains.

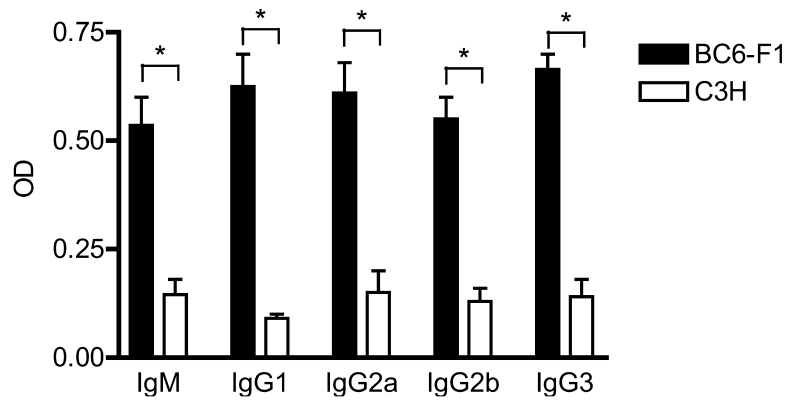

Fig. 4. VSG-specific antibody isotype responses in Trypanosoma b. brucei-infected B6B-F1 or C3H mice. Around the first peak of parasitemia, VSG-specific antibody isotypes were quantified in the plasma of T. b. brucei-infected B6B-F1 or C3H mice. Data (mean \pm SE; $n=5$ ) are representative of 5 independent experiments. Uninfected mice did not produce detectable amounts of VSG-specific antibodies. Asterisks indicate statistically significant difference between the two mouse strains.

course of infection (Fig.3D).

Levels of $\mathrm{NO}$ in plasma from infected $\mathrm{C} 3 \mathrm{H}$ and $\mathrm{B} 6 \mathrm{~B}-\mathrm{F} 1$ mice were next analyzed by measuring nitrite accumulations. Plasma from uninfected B6B-F1 or C3H mice exhibited marginal levels of NO $(\sim 110 \mu \mathrm{M}$, Fig. 3E). In both mouse strains, infection with $T . b$. brucei induced increased plasma NO as compared to levels in uninfected animals. However, plasma levels of NO were significantly higher in $\mathrm{C} 3 \mathrm{H}$ than in $\mathrm{B} 6 \mathrm{~B}-\mathrm{F} 1$ mice throughout the infection $(\mathrm{p}<0.05)$.
T. b. brucei-infected C3H mice have lower plasma levels of VSG-specific antibody isotypes than infected B6B-F1 mice: Levels of Abs against AnTat 1 VSG were measured in the plasma of infected (day 10 pi) B6B-F1 and $\mathrm{C} 3 \mathrm{H}$ mice. Detectable levels of IgM, IgG1, IgG2a, IgG2b and IgG3 Ab isotypes were recorded in both mouse strains (Fig. 4). However, plasma levels of all antibody isotypes recorded were significantly lower in $T$. b. brucei-infected $\mathrm{C} 3 \mathrm{H}$ mice compared to B6B-F1 mice $(\mathrm{p}<0.05)$.

\section{DISCUSSION}

Considering the lack of an effective anti-trypanosome vaccine due to antigenic variation and the socio-economical implications of African trypanosomosis in sub-Saharan Africa, there is urgent need for an efficient control of the disease to serve the millions of people and livestock at risk of contracting trypanosomosis. Consequently, research is now focused on identifying parasite and/or host molecules involved in either control or progression of trypanosomosis. The identification of immune mechanisms involved in parasite and disease control, or conversely those responses that are associated with poor clinical outcome, should facilitate the search for vaccine candidates and subsequent vaccine design strategies against African trypanosomosis [17]. Such studies require animal models that differ sufficiently in their response to trypanosome infection. The present study demonstrated that $\mathrm{B} 6 \mathrm{~B}-\mathrm{F} 1$ and $\mathrm{C} 3 \mathrm{H}$ mice differ in their relative resistance to $T$. $b$. brucei infection. Indeed, whilst $\mathrm{C} 3 \mathrm{H}$ mice exhibited reduced ability to control parasite proliferation in 
circulation and died within 25 days pi, B6B-F1 mice effectively controlled their parasitemia and survived significantly longer. Furthermore, $\mathrm{C} 3 \mathrm{H}$ mice had higher and earlier parasite densities in the peritoneal cavity, spleen and lymph node compartments than their B6B-F1 counterparts [author's unpublished observations]. In aggregate, these observations indicate that $\mathrm{C} 3 \mathrm{H}$ mice are more trypanosusceptible than B6B-F1 mice. Furthermore, in agreement with our previous report [9], it was interesting to note that although trypanosomes were seen in circulation, peritoneal cavity and spleen a few days after infection, the appearance of parasites in the lymph node compartment in both cases coincided with death of mice within a few days, suggesting that the latter compartment could be critical for protection against $T$. b. brucei infection.

We next compared the immune responses in the plasma and lymph node compartments of the two mouse models that differ in their susceptibility to $T$. b. brucei infection. Quantitative differences in the pattern of cytokine and $A b$ production were recorded between the two mouse strains. In agreement with Newson et al. [13], the relatively susceptible $\mathrm{C} 3 \mathrm{H}$ mice exhibited profound suppression in their capacity to produce parasite-antigen-specific Abs of all isotypes. In contrast, B6B-F1 mice that exhibited relative trypanotolerance had significantly higher levels of VSGspecific plasma Abs. These observations support and further highlight the protective role of parasite-antigen-specific Abs during trypanosomosis $[5,7,12]$. Recent studies suggest that Abs of the IgG class, particularly IgG1 and IgG2a, are more closely correlated with trypanotolerance than IgM $[2,7,9,19]$. Such parasite-specific IgG Abs may be crucial in mediating parasite clearance and possibly in the neutralization of potentially pathogenic parasite molecules. On the other hand, increased IgM has been implicated in enhanced trypanosusceptibility in mice [19] and cattle [18]. In trypanosusceptible animals, most of the IgM produced is polyspecific and of low specificity [17]. Such polyspecific Abs may mediate disease progression through induction of host tissue damage including erythrophagocytosis, contributing to anemia development $[17,18]$. Based on that, it is tempting to speculate that Abs of the IgG class, but not IgM, could be involved in the resistance phenotype exhibited by B6B-F1 mice in the present study.

Following stimulation with VSG, C3H-LNCi secreted higher proinflammatory mediators/effectors (IFN- $\gamma$, TNF$\alpha)$ than their B6B-F1 counterparts. Moreover, $\mathrm{C} 3 \mathrm{H}$ mice exhibited higher circulating levels of IFN- $\gamma$, TNF- $\alpha$ and NO during the course of infection. Interestingly, in both compartments, IL-10 was mainly produced during the late phase of the disease, with the relatively resistant B6B-F1 mice secreting comparatively higher levels. Cumulatively, evidence from the present study and other reports $[2,3,11]$ strongly suggests that pro-inflammatory responses are protective mainly against the early phase of murine African trypanosomosis. Indeed, there is large body of evidence suggesting that (i) relative resistance to African trypanosomosis is associated with a Th1 cell response to parasite anti- gens [14], (ii) IFN- $\gamma$ is linked with host resistance [3], and that (iii) TNF- $\alpha$ and NO further contribute to trypanotolerance through direct trypanotoxic mechanisms [4, 7]. This study further suggests that the production of various immune molecules during trypanosomosis is under tight control. Thus, there seems to be a certain range within which pro-inflammatory and associated molecules are protective, above which they become harmful to the host, possibly through host-tissue damage $[11,15]$, and below which they fail to induce an effective parasite control, leading to massive parasitosis $[3,11]$. Of note, the IFN- $\gamma / \mathrm{IL}-10$ balance appears to be critical [11]. Thus, during African trypanosomosis, hypersecretion of IFN- $\gamma$, with a concomitant suppression of IL-10, results in profound increase in the IFN- $\gamma /$ IL-10 ratio, macrophage hyperactivation with excessive TNF- $\alpha$ and NO production and a susceptible phenotype [10]. In agreement with previous reports $[11,15,16]$, IL-10 could play an important role in trypanotolerance by means of checking the levels of IFN- $\gamma$ production during the course of infection.

In conclusion, the differential susceptibility to T. b. brucei by $\mathrm{C} 3 \mathrm{H}$ and $\mathrm{B} 6 \mathrm{~B}-\mathrm{F} 1$ mice may provide a practical model for studying mechanisms underlying resistance and/or susceptibility during African trypanosomosis. The enhanced susceptibility of $\mathrm{C} 3 \mathrm{H}$ mice to $T$. b. brucei may be attributed to their inherent hyperproduction of proinflammatory effectors/mediators with a concomitant reduced ability to mount a strong $\mathrm{Ab}$ response against parasite-specific antigens. Further studies should be directed at characterizing more extensively the innate and adaptive immune responses in the two mouse models following infection with African trypanosomes.

ACKNOWLEDGEMENTS. This work, supported by the Belgian Administration for Developmental Cooperation (BADC/ABOS), UNPD/World Bank, Fund for Scientific Research Flanders (FWO) and Flemish Government (VLAB), was performed as part of an Interuniversity Attraction Pole Program.

\section{REFERENCES}

1. Beschin, A., Brys, L., Magez, S., Radwanska, M. and De Baetselier, P. 1998. Trypanosoma brucei infection elicits nitric oxide-dependent and nitric oxide-independent suppressive mechanisms. J. Leukoc. Biol. 63: 429-439.

2. Drennan, M. B., Stijlemans, B., Van Den Abbeele, J., Quesniaux, V. J., Barkhuizen, M., Brombacher, F., De Baetselier, P., Ryffel, B. and Magez, S. 2005. The induction of a type 1 immune response following a Trypanosoma brucei infection is MyD88-dependent. J. Immunol. 175: 2501-2509.

3. Hertz, C. J., Filutowicz, H. and Mansfield, J. M. 1998. Resistance to the African trypanosomes is IFN- $\gamma$ dependent. $J$. Immunol. 1661: 6775-6783.

4. Iraqi, F., Sekikawa, K., Rowlands, J. and Teale, A. 2001. Susceptibility of tumor necrosis factor-a genetically deficient mice to Trypanosoma congolense infection. Parasite Immunol. 23: $445-451$.

5. Levine, R. F. and Mansfield, J. M. 1982. Serological and 
pathological differences associated with resistance and susceptibility to the African trypanosomes. Fed. Proc. 41: 585.

6. Mabbott, N. A., Sutherland, I. A. and Sternberg, J. M. 1994. Trypanosoma brucei is protected from the cytostatic effect of nitric oxide under in vivo conditions. Parasitol. Res. 80: 687690.

7. Magez, S., Radwanska, M., Drennan, M., Fick, L., Baral, T. N., Brombacher, F. and De Baetselier, P. 2006. Interferon-gamma and nitric oxide in collaboration with antibodies are key protective host immune factors during trypanosome Tc13 infections. J. Infect. Dis. 193: 575-1583.

8. Magez, S., Stijlemans, B., Radwanska, M., Pays, E., Ferguson, M. A. J. and De Baetselier, P. 1998. The glycosyl-inositolphosphate and dimyristoylglycerol moities of the glycosylphosphatidylinositol anchor of the trypanosome variant-specific surface glycoprotein are distinct macrophage-activating factors. J. Immunol. 160: 1949-1956.

9. Namangala, B., De Baetselier, P., Brys, L., Stylemans, B., Noël, W., Pays, E., Carrington, M. and Beschin, A. 2000. Attenuation of Trypanosoma brucei is associated with reduced immunosupression and concomitant production of Th2 lymphokines. J. Infect. Dis. 181: 1110-1120.

10. Namangala, B., De Baetselier, P., Noël, W., Brys, L. and Beschin, A. 2001. Alternative versus classical macrophage activation during experimental African trypanosomosis. J. Leukoc. Biol. 69: 387-396.

11. Namangala, B., De Baetselier, P., Noël, W., Brys, L., Magez, S. and Beschin, A. 2001. Relative contribution of IL-10 and IFN- $\gamma$ towards resistance to African trypanosomosis. J. Infect. Dis. 183: 1794-1800.

12. Namangala, B., Sugimoto, C. and Inoue N. 2007. Effects of exogenous transforming factor $\beta$ on Trypanosoma congolense infectrion in mice. Infect. Immun. 75: 1878-1885.

13. Newsons, J., Mahan, M. S. and Black, J. S. 1990. Synthesis and secretion of immunoglobulin by spleen cells from resistant and susceptible mice infected with Trypanosoma brucei brucei
GUTat 3.1. Parasite Immunol. 12: 125-139.

14. Schleifer, K. W., Filutowicz, H., Schopf, L. R. and Mansfield, J. M. 1993. Characterisation of T helper cell responses to the trypanosome variant surface glycoprotein. J. Immunol. 150: 2910-2919.

15. Shi, M., Pan, W. and Tabel, H. 2003. Experimental African trypanosomiasis: IFN- $\gamma$ mediates early mortality. Eur. J. Immunol. 33: 108-118.

16. Shi, M., Wei, G., Pan, W. and Tabel, H. 2006. Experimental African trypanosomiasis: A subset of pathogenic, IFN- $\gamma$-producing, MHC Class II-restricted $\mathrm{CD}^{+} \mathrm{T}$ cells mediate early mortality in highly susceptible mice. J. Immunol. 176: 17241732.

17. Taylor, K. A. 1998. Immune responses of cattle to African trypanosomes: protective or pathogenic? Int. J. Parasitol. 28: 219-240.

18. Taylor, K., Lutje, V., Kennedy, D., Authie, E., Boulange, A., Logan-Henfrey, L., Gichuki, B. and Gettinby, G. 1996. Trypanosoma congolense: B-lymphocyte responses differ between trypanotolerant and trypanosusceptible cattle. Exp. Prasitol. 83: $106-116$.

19. Uzonna, J. E., Kaushiki, R. S., Gordon, J. R. and Tabel, H. 1999. Cytokines and antibody responses during Trypanosoma congolense infections in two inbred mouse strains that differ in resistance. Parasite Immunol. 21: 57-71.

20. Uzonna, J. E., Kaushiki, R. S., Gordon, J. R. and Tabel, H. 1998. Experimental murine Trypanosoma congolense infections. I. Administration of anti-IFN- $\gamma$ antibodies alters trypanosome-susceptible mice to a resistant-like phenotype. $J$. Immunol. 161: 5507-5515.

21. Uzonna, J. E., Kaushiki, R. S., Gordon, J. R. and Tabel, H. 1998. Immunoregulation in experimental murine Trypanosoma congolense infection: anti-IL-10 antibodies reverse trypanosome-mediated suppression of lympocyte proliferation in vitro and moderately prolongs the lifespan of genetically susceptible BALB/c mice. Parasite Immunol. 20: 293-302. 